\title{
A Rare Case of Suppurative Parotitis with Facial Nerve Palsy
}

\author{
Manoj Kumar Kanzhuly1*, Devendra Kumar Gupta1, Chiyyarath Gopalan Muralidharan² \\ ${ }^{1}$ Department of ENT, Military Hospital, Jalandhar Cantonment, Jalandhar, India \\ ${ }^{2}$ Department of Radiology, Military Hospital, Jalandhar Cantonment, Jalandhar, India \\ Email: manojkanzhuly@gmail.com
}

Received 13 June 2014; revised 12 July 2014; accepted 11 August 2014

Copyright (C) 2014 by authors and Scientific Research Publishing Inc.

This work is licensed under the Creative Commons Attribution International License (CC BY).

http://creativecommons.org/licenses/by/4.0/

c) (i) Open Access

\begin{abstract}
Parotid mass causing facial nerve palsy is rare, and is associated with malignant tumours. Acute infection or abscess leading to facial nerve palsy is an extremely rare complication. A literature review revealed only 16 cases of facial nerve palsy associated with suppurative parotitis or parotid abscess. We present a case of deep parotid abscess which is complicated by facial nerve dysfunction.
\end{abstract}

\section{Keywords}

Parotid Mass, Facial Nerve Palsy, Suppurative Parotitis

\section{Case Report}

A 42-year-old gentleman with no previously known co-morbidities presented in the OPD with painful swelling (R) parotid of 20 days duration, associated with intermittent fever, without chills/rigor. He developed right sided facial asymmetry for 7 days. On examination, he was moderately built and nourished. Systemic examination was within normal limits. Local examination of the $(\mathrm{R})$ parotid area revealed a $6 \times 5 \mathrm{~cm}$ swelling, superficial skin suffused, no scar/sinus/pulsations. It was tender with brawny edema. There was a lower motor neuron type marginal mandibular nerve palsy of (R) Facial Nerve (House-Brackman Grade V), Figure 1. Rest of the peripheral branches of the nerve was normal clinically. No cervical lymphadenopathy was noted. Other salivary glands were normal. Examination of the oral cavity showed trismus with only 2 finger mouth opening. Stensons ductal orifice (R) was congested with no pus or discharge. Digital palpation of the duct revealed no stones. Oral hygiene was satisfactory. There was no evidence of deep neck infections (para pharyngeal/retropharyngeal). Investigation of blood showed neutrophilia $\left(13,000 / \mathrm{mm}^{3}\right)$. Blood culture yielded no growth. Blood sugar fasting was

\footnotetext{
${ }^{*}$ Corresponding author.
}

How to cite this paper: Kanzhuly, M.K., Gupta, D.K. and Muralidharan, C.G. (2014) A Rare Case of Suppurative Parotitis with Facial Nerve Palsy. International Journal of Otolaryngology and Head \& Neck Surgery, 3, $248-251$. 
$340 \mathrm{mg} \%$ and postprandial $480 \mathrm{mg} \%$ indicative of diabetes mellitus type II. Urine sugar was +++ and ketone bodies were negative. Renal and liver function tests were normal. Ultrasonography of the parotid gland showed $6 \times 5 \mathrm{~cm}$ gas filled cystic lesion in the superficial lobe of (R) parotid gland. MRI was done which revealed a gas and fluid filled $7 \times 6 \mathrm{~cm}$ cyst in the superficial lobe of (R) parotid gland (Figure 2). Deep lobe appeared normal. There are no other findings on imaging. He was initially treated with parenteral Amoxicillin with clavulanic acid $1.2 \mathrm{gm}$, Metronidazole $500 \mathrm{mg}$, Inj Plain insulin on sliding scale, analgesics, antipyretics and plenty of oral fluids. He was also given mouth wash and lime juice as sialogouge along with constant massage and hot fomentation of the (R) parotid gland. Patient was counseled regarding progressive VIIN palsy and iatrogenic risk of trauma to nerve during surgery. After consultation with microbiologist regarding fresh plating of pus aspirated and anaerobic culture, we proceeded with surgery. A modified Blair incision was given and flap rose over the (R) parotid area. Per operatively, there was extensive necrosis in the parotid parenchyma and surrounding tissue. Incisions were made over the parotid parenchyma parallel to the course of the facial nerve to avoid nerve trauma. A $6 \times 5 \mathrm{~cm}$ thick walled cyst with foul smelling gas and $10 \mathrm{ml}$ viscid purulent material was seen in the parotid parenchyma. Slough and necrotic tissue were derided till bleeding margins. Attempt was made to identify the facial nerve but due to the slough it was unsuccessful. And intracavitary rubber drain was placed, wound par-

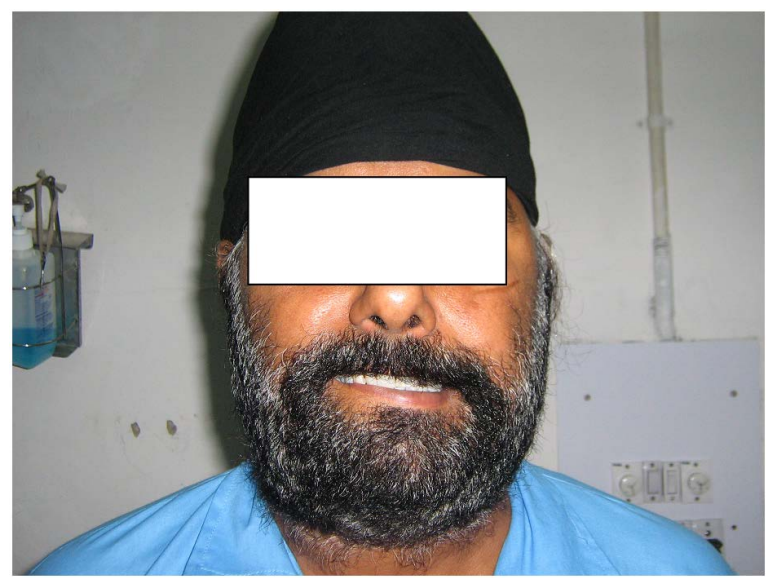

Figure 1. Clinical picture-lower motor neuron type marginal mandibular nerve palsy of (R) facial nerve.

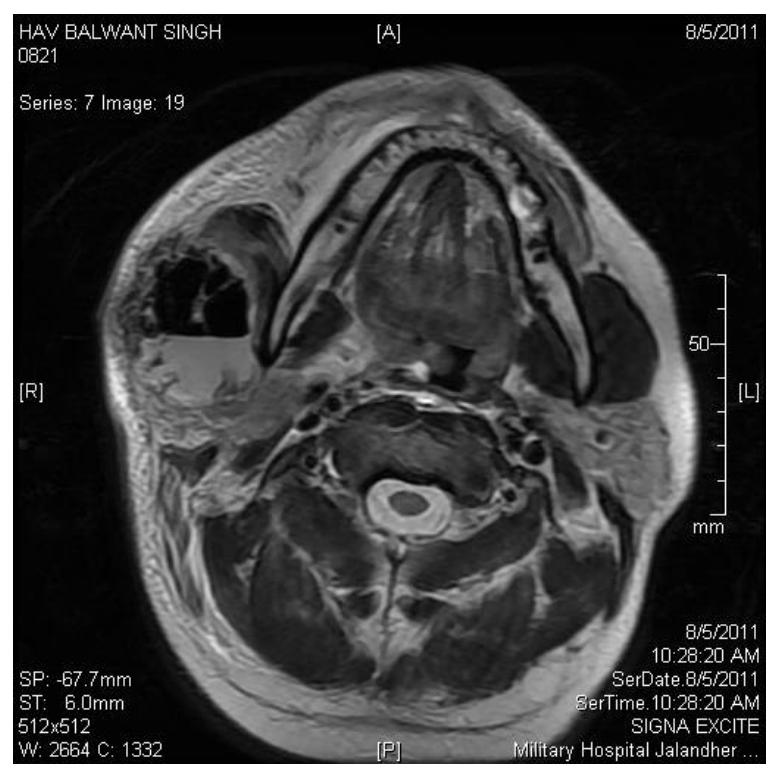

Figure 2. CT axial section-necrotizing parotitis (R) with gas-fluid level. 
tially sutured and pressure dressing was applied. During the immediate post operative period patient status improved, but marginal mandibular palsy persisted. But no new iatrogenic trauma to other branches of facial nerve was noticed. High dose Antibiotics and management of diabetes mellitus continued. Blood sugar was controlled in post op period (fasting sugar $100 \mathrm{mg} \%$ and post prandial $160 \mathrm{mg} \%$ ). Pus culture from the cyst revealed Klebsiella species. Final diagnosis of necrotizing parotitis was made. Patient underwent repeated debridement of slough and finally secondary suturing was done after 10 days and he was put on facial physiotherapy and electrical seventh nerve stimulation. He was finally discharged on oral hypoglycemic agents. On further follow-up, after up to 12 weeks, surgical wound was well healed, marginal mandibular palsy improved to Grade II in the House-Brackman scale.

\section{Discussion}

Parotid gland is prone to infection in conditions like general debility, dehydration etc. The factors implicated in the development of parotitis are oropharyngeal contamination, reduced salivary secretion, ductal obstruction, all in a vicious cycle leading to chronic recurrent sialadenitis and suppuration. Facial nerve being very tardy is mostly uninvolved in inflammatory lesions of the parotid. Moreover in all the reviewed literature there was complete (all branches) facial nerve palsy associated with suppurative inflammation of parotid gland [1]. Our case is unique that only the marginal mandibular branch of the nerve was involved. The most common organisms causing suppurative sialadenitis are Staphylococcus species including MRSA among the aerobic organisms and Peptostreptococcus and klebsiella among the anaerobic ones [2]. Propionibacterium [3] and Candida [4] have also been incriminated. Viral parotitis (EBV [5] and Mumps [6]) can also cause facial nerve palsy. The aetiopathogenesis of facial nerve palsy in a suppurative lesion is considered to be toxic perineuritis, direct pressure, hemorrhage, inflammation and necrosis underlying malignancy or iatrogenic injury [7]. Recovery of facial nerve palsy may range from six weeks [8] which is the earliest in most of the literature review to twelve weeks [9]. Extensive debridement also decreases the chance of full recovery of the facial nerve possibly due to chances of iatrogenic injury.

The complications of acute suppurative parotitis are deep neck space infections/mediastinal empyema, airway compromise, epiglottic/laryngeal edema, thrombophlebitis of IJV, osteomyelitis of mandible/cervical vertebrae, septicemia, facial nerve palsy [10]. Mortality rate in suppurative parotitis is $20 \%-40 \%$. Early surgical intervention is indicated in parotid infections when there is large/increasing pus collection as demonstrated by USG/ Imaging or there is a lack of improvement in clinical status. In our case, the early intervention cured the infection completely and prevented further complications. So far only 16 cases of suppurative parotitis with facial nerve palsy are reported in the literature. This case is reported to highlight the rare complication which can happen in suppurative parotitis and to ascertain the requirement for brisk management of this rapidly progressive and potentially fatal condition. To the best of our knowledge, this is the first case of parotid abscess, with a single facial nerve branch palsy, reported in literature. This case also impresses upon the necessity to look for a predisposing cause which needs correction before the management of suppurative parotitis.

\section{References}

[1] Noorizan, Y., Chew, Y.K., Khir, A. and Brito-Mutunayagam, S. (2009) Parotid Abscess: An Unusual Cause of Facial Nerve Palsy. Medical Journal of Malaysia, 64, 172-173.

[2] Gaio, E., Marioni, G., Ferraro, S.M. and Schwager, K. (2006) Infected Parotid Cyst as a Cause of Facial Palsy. Laryngorhinootologie, 85, 43-45. http://dx.doi.org/10.1055/s-2005-861401

[3] Kristensen, R.N. and Hahn, C.H. (2012) Facial Nerve Palsy Caused by Parotid Gland Abscess. The Journal of Laryngology \& Otology, 126, 322-324. http://dx.doi.org/10.1017/S0022215111002635

[4] Marioni, G., Rinaldi, R., de Filippis, C., Gaio, E. and Staffieri, A. (2003) Candidial Abscess of the Parotid Gland Associated with Facial Nerve Paralysis. Acta Oto-Laryngologica, 123, 661-663. http://dx.doi.org/10.1080/00016480310000449

[5] Hajiioannov, J.K., Flouro, V., Kousoulis, P., Kretzaz, D. and Moshovakis, E. (2013) Reversible Facial Nerve Palsy Due to Parotid Abscess. International Journal of Surgery Case Reports, 4, 1021-1024. http://dx.doi.org/10.1016/j.ijscr.2013.08.016

[6] Endo, A., Izumi, H., Miyashita, M., Okubo, O. and Harada, K. (2001) Facial Palsy Associated with Mumps Parotitis. The Pediatric Infectious Disease Journal, 20, 815-816. http://dx.doi.org/10.1097/00006454-200108000-00023 
[7] Athar, P.P.S.H., Yahya, Z., Baki, M.M. and Abdullah, A. (2009) Facial Nerve Paralysis: A Rare Complication of Parotid Abscess. Malaysian Journal of Medical Sciences, 16, 38-39.

[8] Maier, H., Attallah, M. and Junemann, K.H. (1990) Facial Paralysis in Chronic Nonspecific Inflammation of the Parotid. $H N O, \mathbf{3 8}, 38-40$.

[9] Orhan, K.S., Demirel, T., Orhan, K. and Kulak, Y.K. (2008) Facial Paralysis Due to an Occult Parotid Abscess. Kulak Burun Boğaz İhtisas Dergisi, 18, 115-117.

[10] Andrews, J.C., Abemayor, E., Alessi, D.M. and Canalis, R.F. (1989) Parotitis and Facial Nerve Dysfunction. Archives of Otolaryngology—Head and Neck Surgery, 115, 240-242. 
Scientific Research Publishing (SCIRP) is one of the largest Open Access journal publishers. It is currently publishing more than 200 open access, online, peer-reviewed journals covering a wide range of academic disciplines. SCIRP serves the worldwide academic communities and contributes to the progress and application of science with its publication.

Other selected journals from SCIRP are listed as below. Submit your manuscript to us via either submit@scirp.org or Online Submission Portal.
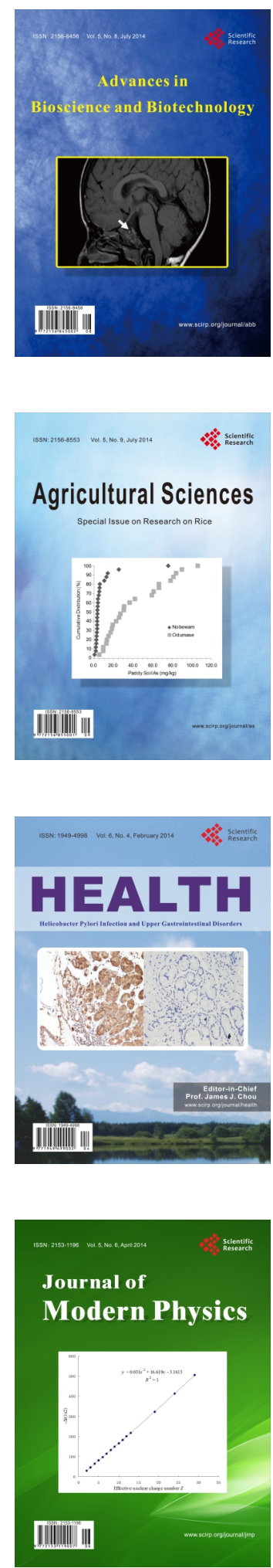
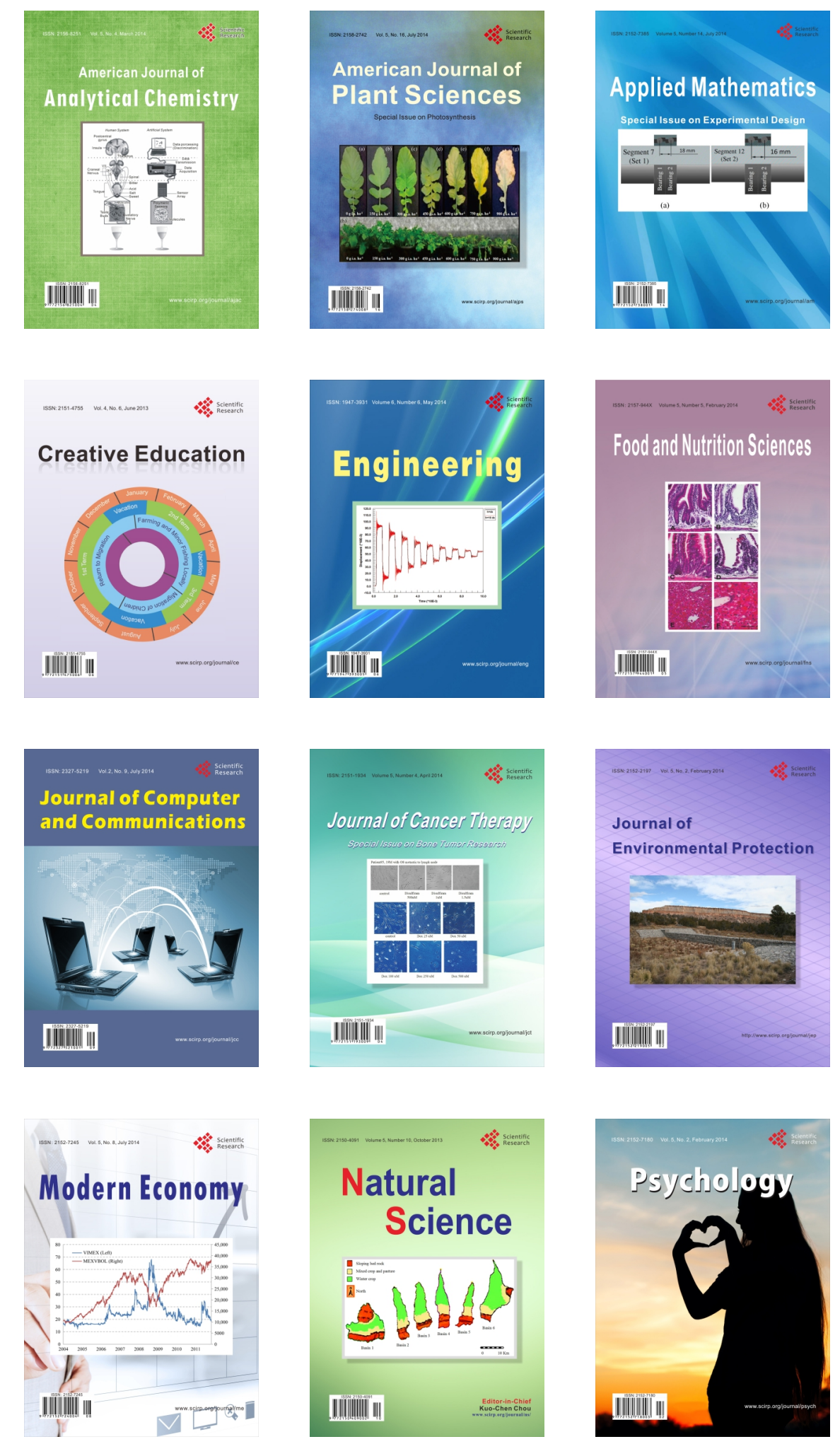